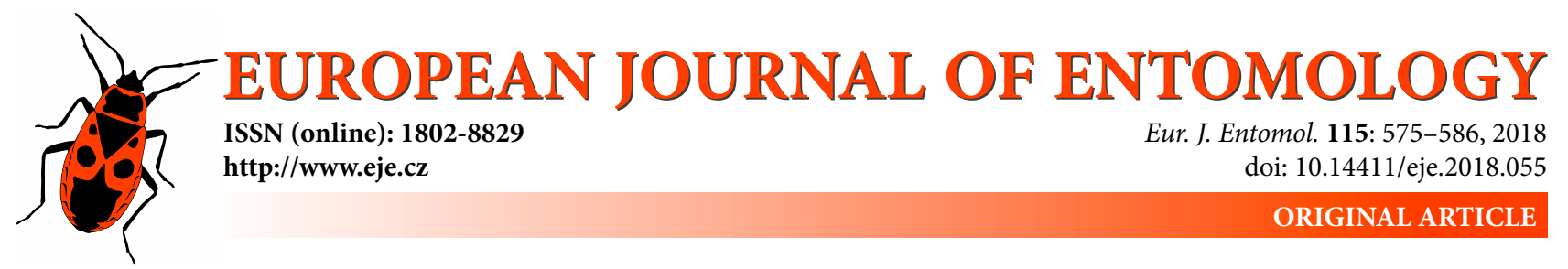

\title{
Distribution and dispersal of the invasive Asian chestnut gall wasp, Dryocosmus kuriphilus (Hymenoptera: Cynipidae), across the heterogeneous landscape of the Iberian Peninsula
}

\author{
Diego GIL-TAPETADO ${ }^{1,2}$, José F. GÓMEZ² ${ }^{\text {, Francisco J. CABRERO-SAÑUdO }}{ }^{2}$ and José L. NIEVES-ALDREY ${ }^{1}$ \\ ${ }^{1}$ Museo Nacional de Ciencias Naturales, José Gutiérrez Abascal 2, Madrid 28006, Spain; e-mail: mcnna38@mncn.csic.es \\ 2 Universidad Complutense de Madrid, Comunidad de Madrid, Spain; e-mails: diego.gil@ucm.es, jf.gomez@bio.ucm.es, \\ fjcabrero@bio.ucm.es
}

Key words. Hymenoptera, Cynipidae, Dryocosmus kuriphilus, Asian chestnut gall wasp, invasive species, niche models, dispersal, distribution, Iberian Peninsula

\begin{abstract}
Dryocosmus kuriphilus (Hymenoptera: Cynipidae), also known as the Asian chestnut gall wasp, is a non-native invasive species that has recently appeared in many regions of Europe, including the Iberian Peninsula. This species is an important pest of chestnut trees in several regions and is of concern for foresters in these areas. The results of this research revealed 14 different hotspots of infestation of $D$. kuriphilus and resulted in the development of models that predict the distribution of $D$. kuriphilus in Spain over the next 37 years (2019-2055). These results indicate a rapid spread in all Spanish chestnut forests and identify areas that are theoretically highly suitable and susceptible to colonization by this cynipid based on predictions of three different niche models. Although $D$. kuriphilus is able to induce galls on all chestnut trees, the models indicate that there are differences in the suitability of the different regions for this species. This differential suitability results in some areas having better environmental conditions than others for $D$. kuriphilus, which is a factor that should be taken into account in its management and biological control. This study of the current distribution, patterns of dispersal using GIS and potentially suitable areas for $D$. kuriphilus, using niche models will assist in the management and control of this pest in Spain.
\end{abstract}

\section{INTRODUCTION}

The Asian chestnut gall wasp, Dryocosmus kuriphilus Yasumatsu, 1951 (Hymenoptera: Cynipidae), is a cynipid species native to southern China, where it induces galls on all species of Castanea Mill. (Fagaceae). Taxonomically, it is included in the tribe Cynipini (Hymenoptera: Cynipidae), a large group of cynipids commonly known as oak gall wasps, with approximately 1000 species that induce galls on plants in the family Fagaceae, especially Quercus L. (Nieves-Aldrey, 2001). Dryocosmus kuriphilus is univoltine, involving parthenogenetic thelytokous reproduction, which means that only females are known. The adult females are small insects of approximately $2 \mathrm{~mm}$ in length and their life expectancy is only approximately ten days. Adults emerge from galls between May and August and lay eggs in chestnut buds that will develop into galls the next spring (Yasumatsu, 1951; CABI, 2015), which prevents the formation of healthy shoots and leaves (Maltoni et al., 2012).

Dryocosmus kuriphilus induces galls on new shoots, stipules and leaves of chestnut (Castanea spp.). It has been reported that $D$. kuriphilus adversely affects chestnut trees by reducing fruit production by up to $80 \%$ (EFSA,
2010), modifying plant architecture (Gehring et al., 2017) and even rarely negatively affecting the survival of trees (Payne et al., 1975). This cynipid is distributed in different regions around the world where chestnut forests are present, such as Japan (Oho \& Umeya, 1975), North America (Payne et al., 1975) and Europe (Brussino et al., 2002).

Gall wasp proliferation and invasiveness in newly colonized areas is facilitated by the absence of natural enemies (Stone et al., 2002). Despite the recruitment of numerous indigenous parasitoids by $D$. kuriphilus after its arrival in Europe, which shifted onto this new resource from the Cynipini parasitoid communities on oaks, none were able to control this invasive species (Aebi et al., 2006, 2007; Cooper \& Rieske, 2007; Quacchia et al., 2012). As these native parasitoids are not effective in controlling the abundance of D. kuriphilus, there have been attempts to control it using its natural enemy, Torymus sinensis Kamijo, 1982 (Hymenoptera: Torymidae) (Moriya et al., 1989; Murakami et al., 2001). This torymid, also a native of China, has been used in different countries against $D$. kuriphilus with good results (Moriya et al., 2003; Cooper \& Rieske, 2007; Quacchia et al., 2012; Matošević et al., 2016; Ferracini et al., 2018). 
In addition to short-distance dispersal (SDD) by flying and wind-assisted passive transportation (Graziosi \& Rieske, 2012), the dispersal of D. kuriphilus has also been facilitated by passive long-distance dispersal (LDD). Such dispersal mainly occurs through the trade in and transport of infested chestnut trees from chestnut nurseries. These chestnut trees have dormant buds in which D. kuriphilus had previously laid eggs in their place of origin (Bernardo et al., 2013). LDD is considered to be the most important factor determining the dispersal of D. kuriphilus, especially the colonization of distant areas (Quacchia et al., 2008; Gilioli et al., 2013). By this means of dispersal, D. kuriphilus arrived in Catalonia in 2012 (northeast Iberian Peninsula) (EPPO, 2012; Pujade-Villar et al., 2013), spread to other Spanish regions, such as Galicia (northwest Iberian Peninsula) and Málaga (Andalusia, southern Iberian Peninsula), and arrived in Portugal in 2014 (EPPO, 2014). Some authors have suggested that the rapid spread of $D$. kuriphilus is related to the genetics of the European populations of this species (Bonal et al., 2018: Avtzis \& Matosevic, 2013).

Chestnut trees in Spain occur in the wet northern part of the country, except the Pyrenees; they are also present in the Midwest and southern half of Spain, although a few trees are also found in various urban areas and gardens throughout Spain. Therefore, all the mentioned areas are likely to be susceptible to $D$. kuriphilus and should also be monitored and managed.

One of the most important tools that can be used for monitoring invasive species in different areas are species distribution models, which assess the potential of a region for invasion (Jiménez-Valverde et al., 2011). By overlapping different climatic variables and the current distribution of a species, it is possible to infer the requirements or ecological preferences of D. kuriphilus, such as, optimal temperatures (Bonsignore \& Bernardo, 2018). Taking this into account, predictions regarding the presence or absence of populations in a particular area can be made using mathematical models that describe the potential distributions of species. For this gall-inducing species, the distribution of its hosts can be used as a predictor of its potential distribution (Nieves-Aldrey et al., 2006; Rodriguez et al., 2015).

Therefore, updating the knowledge on gall wasp occurrence in Spain and providing tools for monitoring its spread may fill the gaps in its geographic distribution and will facilitate management. In this study, we aim to (a) characterize the current distribution of D. kuriphilus in Spain, (b) predict the spread of this species regarding only its SDD, taking into account that there are no new LDD events that affect their natural dispersal., and (c) identify the most suitable areas in Spanish forests using niche models.

\section{MATERIALS AND METHODS}

\section{Current distribution of $D$. kuriphilus in Spain}

We obtained georeferenced, nation-wide and unpublished records from the Spanish Ministry of Agriculture (MAGRAMA, 2015), departments of forests and biodiversity of Catalonia (MNBC, 2015) and Andalusia (JAND, 2015), research by Perez-Otero et al. (2017) and the Biodiversidad Virtual database (BVdb) (BVdb, 2018a). These 24,916 georeferenced records of D. kuriphilus in Spain were combined in two maps showing where this species of cynipid was present, one for 2012 to 2015 , the early period of the spread, and another for 2012 to 2018, the current distribution. Most of the records are for the Catalonian region (Fig. 1A) mainly because of the quality of the information provided by MNBC. As the number of records per unit area for Catalonian was higher than that for other regions, a lower number of records was used to homogenize the number of locations where D. kuriphilus was present. This method prevents a possible bias that would result if all 414 locations for Catalonian were used to evaluate the model performance as it would suppress other data on the niche of D. kuriphilus in this region. Maximum and minimum values of each climatic variable for all the records for the Catalonian region were taken into account, and equal proportions of data points were selected for each area (Fig. 2).

Based on the information available up to 2018, it is assumed that, in the absence of any control of $D$. kuriphilus, this cynipid wasp is still present and abundant in areas where it was recorded in previous years. In addition, D. kuriphilus has been able to spread by SDD and colonize adjacent areas.

A map of the distribution of $C$. sativa was created using georeferenced records from different sources: the GBIF (Global Biodiversity Information Facility) (GBIF Data Portal, 2018), MAGRAMA (unpublished data) and BVdb (BVdb, 2018b). Data from GBIF and BVDB were appropriately processed and filtered, and possible inconsistencies, such as locations with very low georeferenced accuracy or errors, were deleted and only the records from the period 1997 to 2018 were selected for homogenization with other records. All these chestnut tree records were used to predict the spread and potential distribution of D. kuriphilus in Spain.

This dataset constitutes an approximation of the current distribution of chestnut trees in Spain, especially the large number of trees of commercial interest and those of public heritage. However, it is assumed that some chestnut trees were not included because they were not georeferenced or referenced in official and inaccessible data sources.

Differences among values of bioclimatic variables for Spain were analyzed using a paired Student t-tests with a Bonferroni correction based on a similar number of locations for each of the regions considered.

\section{Models of dispersal of $\boldsymbol{D}$. kuriphilus}

The models were used to identify chestnut trees that could theoretically be threatened by $D$. kuriphilus in the next 37 years (2019-2055). These models were constructed using the distribution map of all the records of $C$. sativa in Spain, the values of the mean annual linear rate of SDD for D. kuriphilus $(6.6 \mathrm{~km} /$ year $)$, and the maximum annual rate of $11 \mathrm{~km} /$ year based on the results of Gilioli et al. (2013). Due to a lack of data regarding the mean rate of dispersal for this cynipid species in Spain, the information derived from this approach was used to determine the annual rate of dispersal in threatened areas. Previous research, such as that of Gilioli et al. (2013), provides many parameters describing the dispersal of D. kuriphilus. However, in Spain, research on this pest began only recently and there are several factors that can affect the dispersal of $D$. kuriphilus (Fernandez-Conradi et al., 2017), which have not yet been measured. Other examples of parameters that can influence the dispersal of $D$. kuriphilus are wind, precipitation and temperature. In fact, the annual range of high temperatures may affect $D$. kuriphilus development and activity (Bonsignore \& Bernardo, 2018) because, as D. kuriphilus is an ectotherm, low temperatures can limit or reduce its dispersal, while high temperatures can increase its dispersal ability. We aimed to study these aspects because of the lack of previous 


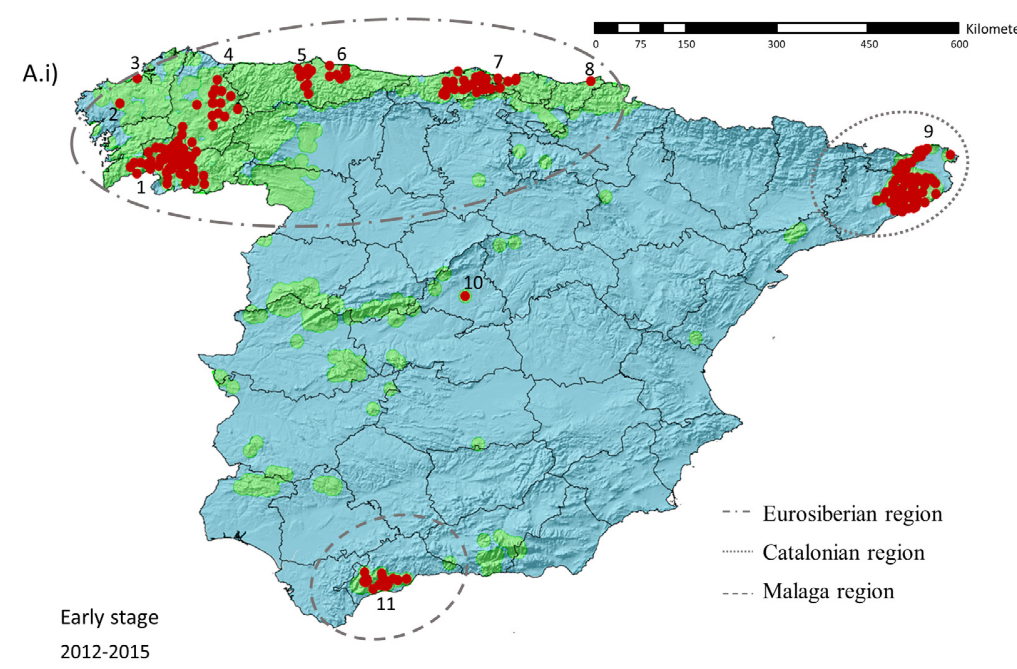

B)
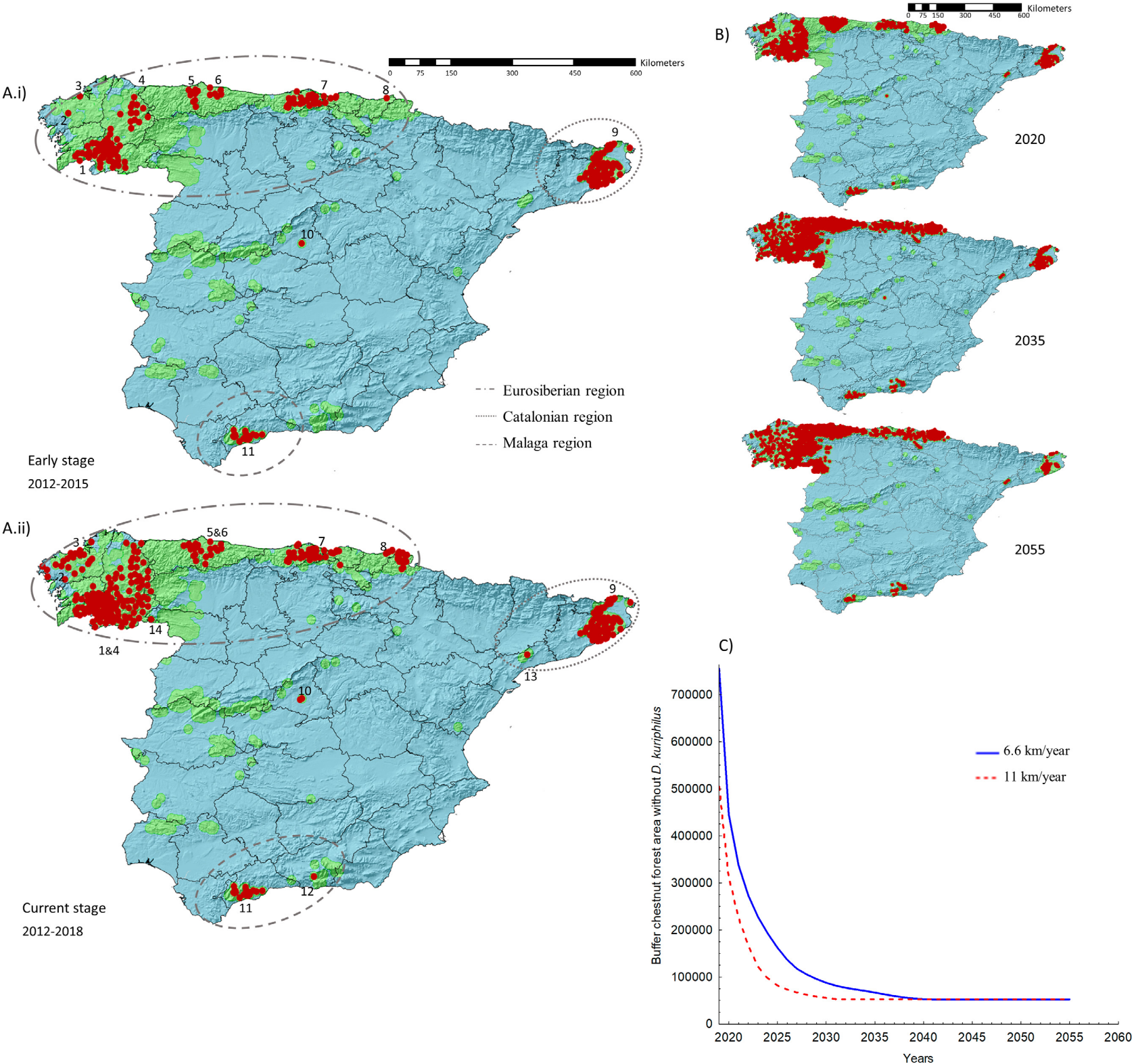

Fig. 1. A.i: Map showing the distribution of $D$. kuriphilus early in its colonization of Spain (up to April 2015). Red spots indicate the presence of $D$. kuriphilus, green spots uninfested chestnuts. Circles indicate infestation hotspots: 1 - West Ourense and East Pontevedra, 2 - Val do Dubra, 3-A Coruña, 4-East Lugo, 5 and 6 - central areas of Asturias, 7 - East Cantabria and West Vizcaya, 8 - Pasajes (Guipuzcoa), 9 - Catalonia, 10 - Madrid, and 11 - Sierra de las Nieves. A.ii: Current distribution of $D$. kuriphilus (up to May 2018). The current hotspots are 1\&4 - West and South Galicia and El Bierzo, 2 - Val do Dubra, 3 - A Coruña, 5\&6 - Central Asturias, 7 - East Cantabria and West Vizcaya, 8 - East Cantabria and West Basque Country, 9 - Catalonia, 10 - Madrid, 11 - Sierra de las Nieves, 12 - Lanjarón, 13 - Prades, and 14 - Alta Sanabria. B: Predicted gall wasp distribution in 2020, 2025 and 2035 using a mean SDD of 6.6 km/year. C: Predicted decrease in non-infested chestnut trees from 2019 to 2055 . The solid line is that obtained using a mean rate of dispersal of $6.6 \mathrm{~km} / \mathrm{year}$, while the dashed line the maximum rate of $11 \mathrm{~km} /$ year.

studies on infestation rates of $D$. kuriphilus in Spain. The probability that an individual would infest a chestnut tree within its range of dispersal was based on the maximum distance it is able to disperse. For these models, LDD was not considered because it is impossible to predict.

The annual increase in the distribution of D. kuriphilus in Spain was analyzed using a buffer tool based on the total set of locations where it was present. This method used 6.6 and $11 \mathrm{~km} /$ year as the annual mean and maximum rates, respectively, to obtain the possible dispersal or influence area. By overlapping the buffers surrounding chestnut trees, new infestations of chestnut trees in subsequent years were predicted. This process was repeated itera- tively until predictions for ten years were obtained. ArcGIS 10.1 (ESRI, 2010) software was used to generate the maps.

A graph of the estimated fitted curves of the infestation rate was also created, which shows that the area over which $C$. sativa occurs where $D$. kuriphilus is absent would decrease due to the possible expansion of the species each year based on the dispersal values. The estimated area was calculated using the overall trend in D. kuriphilus dispersal, which can stabilize at an asymptote or intersect the y-axis, indicating that it would hypothetically be able to infest all the chestnut trees in this area. These fitted curves were obtained using CurveExpert Professional 2.4 (Hyams, 2010). 


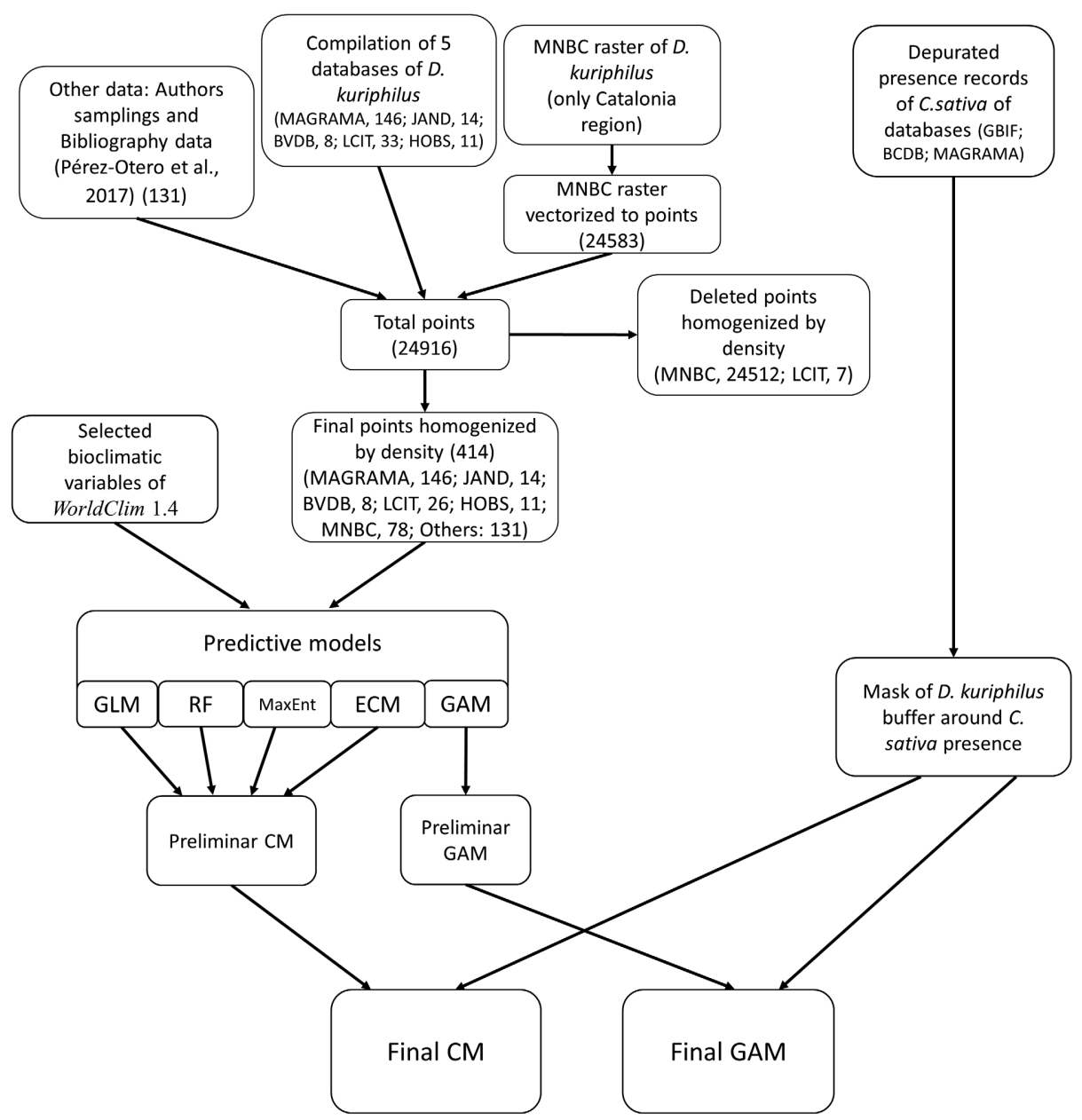

Fig. 2. PRISMA diagram of the methodology used in this study. This diagram includes the documentation of the search, the inclusion process and criteria for homogenizing the presence records, and a summary of the predictions of the models.

\section{Models of the distribution of $\boldsymbol{D}$. kuriphilus}

For a better understanding of the incidence of D. kuriphilus and its possible future spread throughout Spain, five different types of predictive distribution models were constructed. The models were a generalized linear model (GLM), generalized additive model (GAM) (Guisan et al., 2002), random forest (RF) model (Breiman, 2001), maximum entropy (MaxEnt) model (Phillips et al., 2006; Phillips \& Dudik, 2008) and environmental coverage model (ECM) (Jiménez-Valverde et al., 2011).

Furthermore, since all the records refer to galls on chestnut trees, it must be considered that the presence or absence of chestnut trees cannot be considered as a simple variable in the model but has to be considered as a limiting variable (Rodríguez et al., 2015). This means that at any point where chestnut trees were not recorded, the presence of $D$. kuriphilus galls could also not be recorded, even though dispersing adults of D. kuriphilus could potentially be found there. To solve this problem, this cynipid was considered a priori to be unable to disperse beyond the maximum or mean SDD values. Consequently, buffer areas around infested chestnut trees or with a high probability of infestation with the chestnut wasp were identified. This total buffer area of influence of D. kuriphilus was used as a limit on the preliminary models (Fig. 2).

The selection of bioclimatic variables was determined by the phenology of the adult cynipid. The adult stage occurs only for a short period of time, between May and August (Bernardo et al., 2013; Pérez-Otero et al., 2017), with the highest abundance in Spain recorded in the months of June and July (Gil-Tapetado et al., unpubl. data); therefore, only summer variables were used in this analysis. Therefore, the chosen summer variables were extracted from WorldClim version 1.4 (Hijmans et al., 2005) at a scale of 30 arc seconds (Table 1). The variables bio08 (Mean Temperature in Wettest Quarter) and bio09 (Mean Temperature in Driest Quarter) were not included in the analysis due to their anomalous pattern in Spain and the great difference in values for areas that were very close together. Later, an iterative variance inflation factor (VIF) (Lin et al., 2011) analysis was conducted, which deleted correlated variables (VIF $>5$ ). The chosen and non-correlated bioclimatic variables were bio03 (Isothermality), bio07 (Temperature Annual Range), bio16 (Precipitation of Wettest Quarter), bio17 (Precipitation of Driest Quarter).

ECMs are potential distribution models that take into account the fundamental niche, i.e., the potential suitability of an area, depending on the ranges in the values of the environmental variables for the habitat in which a species is located. Following Jiménez-Valverde et al. (2011), all bioclimatic variables were transformed, normalized and checked to verify that there were no discrepancies among them using the software Biomapper (Hirzel et al., 2007). Then, an iterative ecological niche factor analysis (Hirzel et al., 2002) was performed to obtain factors and eliminate redundant information. The correlations between bioclimatic variables are represented by a similarity dendrogram that includes only those that were not auto correlated. Subsequently, following the broken stick criterion used in the program, the first 6 factors were selected. Using these 6 factors, a discriminant model (using presences and pseudo absences) was generated in STATISTICA 
Table 1. Bioclimatic variables from WorldClim 1.4 (except bio08 and bio09) and the altitude and codes used to refer to them in this study. The variables used in the environmental coverage model (ECM) are indicated by 1, while the variables used in the generalized linear (GLM), environmental coverage (ECM), maximum entropy (MaxEnt) and random forest (RF) models are indicated by 2. Mean, standard deviation (SD), and maximum (MAX) and minimum values (MIN) for the locations where $D$. kuriphilus is present in all regions and three different regions in Spain (Euro Siberian, Catalonian and Malaga) are also included in the description of the area occupied by this cynipid wasp.

\begin{tabular}{|c|c|c|c|c|c|c|c|c|c|c|c|c|c|c|c|c|}
\hline \multirow{2}{*}{ Variable } & \multirow{2}{*}{ Code } & \multicolumn{4}{|c|}{ Total regions } & \multicolumn{4}{|c|}{ Euro Siberian region } & \multicolumn{4}{|c|}{ Catalonian region } & \multicolumn{3}{|c|}{ Malaga region } \\
\hline & & MEAN & SD & MAX & MIN & MEAN & SD & MAX & MIN & MEAN & SD & MAX & $\mathrm{MIN}$ & MEAN & SD & MAX MIN \\
\hline Altitude & Alt & 465.1 & 300.2 & 147 & -1 & 403.6 & 276.9 & 91447 & -1 & 305.92 & 256.7 & 934 & 1 & 750.8 & 189.0 & 1145115 \\
\hline Annual mean temperature ${ }^{1}$ & bio01 & 13.5 & 1.5 & 17.9 & 7.7 & 12.7 & 1.2 & 14.9 & 7.7 & 14.4 & 1.3 & 16.2 & 11 & 14.8 & 0.9 & 17.913 .1 \\
\hline $\begin{array}{l}\text { Mean diurnal range [mean of monthly } \\
(\text { max temp-min temp) }]^{1}\end{array}$ & bio02 & 8.6 & 1.4 & 11.8 & 5.8 & 8.4 & 1.2 & 10.3 & 5.8 & 7.3 & 0.4 & 8.7 & 6.9 & 10.3 & 0.4 & 11.88 .6 \\
\hline Isothermality (bio02 $\cdot$ bio07) $\cdot 100^{1,2}$ & bio03 & 3.8 & 0.3 & 4.4 & 3 & 3.9 & 0.2 & 4.4 & 3.5 & 3.1 & 0.1 & 3.5 & 3 & 4.0 & 0.0 & $4 \quad 3.8$ \\
\hline Temperature seasonality (standard deviation $\cdot 100)^{1}$ & ${ }^{1}$ bio04 & 481.6 & 63.9 & 664.5 & 319.4 & 446.1 & 57.1 & 549.13 & 319.4 & 546.6 & 10.7 & 576.7 & 515.5 & 522.1 & 20.5 & 626457 \\
\hline Max temperature of warmest month ${ }^{1}$ & bio05 & 26.0 & 2.3 & 31.1 & 22.1 & 24.5 & 1.3 & 28.2 & 22.1 & 26.8 & 1.1 & 28.2 & 23.8 & 29.3 & 0.3 & 31.129 .1 \\
\hline Min temperature of coldest month ${ }^{1}$ & bio06 & 35.2 & 17.1 & 7.9 & -2.1 & 3.4 & 1.9 & 7.9 & -2.1 & 3.9 & 1.3 & 5.8 & 0.3 & 3.7 & 1.2 & $7.6 \quad 0.4$ \\
\hline Temperature annual range (bio05-bio06) ${ }^{1,2}$ & bio07 & 22.5 & 2.9 & 30.7 & 15.2 & 21.1 & 2.8 & 26 & 15.2 & 22.9 & 0.6 & 24.8 & 22 & 25.6 & 1.1 & 30.722 .1 \\
\hline Mean temperature of warmest quarter ${ }^{1}$ & bio10 & 19.9 & 1.8 & 24.2 & 14.8 & 18.6 & 0.9 & 21.1 & 14.8 & 21.6 & 1.2 & 23.1 & 18.3 & 21.9 & 0.6 & 24.221 .5 \\
\hline Mean temperature of coldest quarter & bio11 & 7.6 & 1.6 & 12.3 & 1.6 & 7.3 & 1.7 & 10.7 & 1.6 & 7.7 & 1.3 & 9.6 & 4.6 & 8.6 & 1.1 & 12.35 .7 \\
\hline Annual precipitation & bio12 & 952.5 & 225.0 & 1557 & 444 & 1098.7 & 167.8 & 1557 & 765 & 763.7 & 73.8 & 916 & 564 & 718.7 & 42.2 & 786546 \\
\hline Precipitation of wettest month & bio13 & 130.5 & 31.1 & 242 & 56 & 148.4 & 27.5 & 242 & 102 & 98.9 & 6.9 & 110 & 81 & 108.6 & 5.3 & 11971 \\
\hline Precipitation of driest month & bio14 & 28.2 & 17.1 & 70 & 1 & 35.3 & 12.6 & 70 & 16 & 36.7 & 7.0 & 51 & 19 & 2.8 & 0.7 & 81 \\
\hline Precipitation seasonality (coefficient of variation) ${ }^{1}$ & bio15 & 41.6 & 16.1 & 72 & 19 & 37.0 & 8.9 & 49 & 20 & 25.0 & 4.1 & 35 & 19 & 67.1 & 2.0 & $72 \quad 51$ \\
\hline Precipitation of wettest quarter ${ }^{2}$ & bio16 & 354.2 & 84.3 & 606 & 156 & 400.5 & 71.3 & 606 & 268 & 240.0 & 13.5 & 264 & 200 & 323.4 & 17.5 & 352201 \\
\hline Precipitation of driest quarter ${ }^{2}$ & bio17 & 114.2 & 60.7 & 259 & 16 & 139.1 & 42.7 & 259 & 75 & 149.2 & 19.7 & 186 & 94 & 21.4 & 2.1 & 3316 \\
\hline Precipitation of warmest quarter ${ }^{1}$ & bio18 & 128.9 & 67.2 & 278 & 21 & 152.6 & 48.8 & 278 & 75 & 176.7 & 26.4 & 223 & 118 & 29.6 & 2.7 & 3321 \\
\hline Precipitation of coldest quarter ${ }^{1}$ & bio19 & 321.1 & 104.2 & 596 & 127 & 373.5 & 85.5 & 596 & 205 & 159.6 & 11.6 & 186 & 127 & 311.2 & 18.5 & 341199 \\
\hline
\end{tabular}

(Statistica-StatSoft Inc, 2009). By means of the second Mahalanobis distance (Farber \& Kadmon, 2003), the environmental favourability for D. kuriphilus was calculated for each location. A location was considered to be potentially suitable for this species if its favourability was similar to or higher than the lowest favourability recorded for the localities where it was present, and a favourability map was generated. Moreover, using the calculated factors and presence data for D. kuriphilus, a raster layer was obtained using the algorithm BIOCLIM (Hijmans et al., 2005) implemented in the program DIVA-GIS (Hijmans et al., 2004) Finally, an ECM model map was generated in ArcGIS, which combined the favourability map and the BIOCLIM model.

The GLMs, GAMs and RF models were analyzed using R version 3.3.1 (R Development Core Team, 2008) in RStudio 0.99.903 (RStudio Team, 2016) using the dismo 1.1-4 (Hijmans et al., 2017), mgcv 1.8-23 (Wood, 2018) and randomForest 4.614 (Breiman \& Cutler, 2018) packages. The MaxEnt models were constructed using the Maximum Entropy Species Distribution Modelling software, version 3.4.1 (Phillips et al., 2006; Phillips $\&$ Dudik, 2008). The Area under curve (AUC) values (Fielding $\&$ Bell, 1997) and explained deviance/variance of all models are presented in Table 2. The AUC values for the model evaluation were calculated using a random $30 \%$ of the total number of locations where $D$. kuriphilus was present.

A consensus model (CM) was also constructed using averages from the GLM, GAM, MaxEnt model, RF model and ECM. The decision regarding which models to include in this ensemble was made according to (1) the standard deviation per pixel of each resulting consensus model resulting from the combination of different models and (2) the comparison among models according to pixel favourability values based on the Euclidean dissimilarity

Table 2. Summary of the results of the four models used to construct the consensus model. This summary includes the type of absence (Type), percentage of the deviance or variance explained (Exp.Dev/Var \%), and (AUC) values of the area under the curve for each model.

\begin{tabular}{cccc}
\hline Model & Type & Exp.Dev/Var (\%) & AUC \\
\hline GLM & Weighted background & 57 & 0.70 \\
ECM & Only presences & 95 & - \\
RF & Pseudo absences & 80 & 0.96 \\
MAXENT & Weighted background & - & 0.86 \\
\hline
\end{tabular}

distance among the individual models. Similar models were included in CM in order to obtain a prediction of the favourability for this species, whereas dissimilar models were considered as different hypotheses.

\section{RESULTS}

\section{Current distribution of $\boldsymbol{D}$. kuriphilus in Spain}

The map of the distribution of D. kuriphilus in Spain, which includes all the records available in May 2018, reveals that this species has a disjunct distribution (Fig. 1A), likely caused by LDDs due to human activity, such as chestnut forestry, although sporadically isolated trees can become infested resulting from SDD. The hotspots of $D$. kuriphilus occur in three different regions in this country: one Euro Siberian area and two separate Mediterranean areas; the regions of Catalonia and Malaga. In the early stages of colonization by D. kuriphilus in 2015, there were eleven different areas where the chestnut wasp was present in Spain, 8 in the Euro Siberian region of Spain (1-8) and 3 in the two Mediterranean regions (9-11): West Ourense and East Pontevedra (1), Val do Dubra (A Coruña) (2), A Coruña (3), East Lugo (4), central Asturias (in two separate areas, 5 and 6), East Cantabria and West Basque Country (7), Navarra and East Basque Country (8), Catalonia (Barcelona and Gerona) (9), Madrid (10) and Valle del Genal and Sierra de las Nieves (Malaga) (11) (Fig. 1A). Currently, in 2018, the spread of $D$. kuriphilus by SDD into adjacent areas has occurred as the hotspots 1 and 4 have become one continuous hotspot $(1 \& 4)$ as well as has the hotspots 5 and $6(5 \& 6)$. Hotspot $1 \& 4$ now includes the region of $\mathrm{El}$ Bierzo, along with Galicia, one of the most important areas for producing chestnuts. Hotspot 8 , in the north, has become a continuous area of infected chestnut trees extending towards the south of France. In addition, there are two new hotspots in the Mediterranean region, Lanjarón (12), Prades (13), and one new hotspot in the Euro Siberian region, Alta Sanabria (14). It has also been recorded infesting trees in the central area of Spain, such as, the Tiétar valley 
Table 3. Summary of the results of the paired student t-tests between bioclimatic variables from WorldClim 1.4 and altitude for three different regions where $D$. kuriphilus is present. Eur is the Euro Siberian region, Cat the Catalonian region, and Mal the Malaga region.

\begin{tabular}{|c|c|c|c|c|c|c|c|c|c|}
\hline & ables & t-value & $p$ & & & ables & t-value & $p$ & \\
\hline & Cat vs. Eur & -2.366 & 0.021 & * & & Cat vs. Eur & 12.828 & 0.000 & ** \\
\hline \multirow[t]{3}{*}{ Alt } & Cat vs. Mal & -7.857 & 0.000 & ** & bio10 & Cat vs. Mal & -1.200 & 0.234 & \\
\hline & Eur vs. Mal & -5.612 & 0.000 & ** & & Eur vs. Mal & -16.673 & 0.000 & ** \\
\hline & Cat vs. Eur & 6.973 & 0.000 & ** & & Cat vs. Eur & 2.198 & 0.031 & * \\
\hline \multirow[t]{3}{*}{ bio01 } & Cat vs. Mal & -1.519 & 0.133 & & bio11 & Cat vs. Mal & -3.052 & 0.003 & * \\
\hline & Eur vs. Mal & -9.041 & 0.000 & ** & & Eur vs. Mal & -4.982 & 0.000 & ** \\
\hline & Cat vs. Eur & -5.235 & 0.000 & ** & & Cat vs. Eur & -10.492 & 0.000 & ** \\
\hline \multirow[t]{3}{*}{ bio02 } & Cat vs. Mal & -27.835 & 0.000 & ** & bio12 & Cat vs. Mal & 2.891 & 0.005 & * \\
\hline & Eur vs. Mal & -8.226 & 0.000 & ** & & Eur vs. Mal & 12.729 & 0.000 & ** \\
\hline & Cat vs. Eur & -21.909 & 0.000 & ** & & Cat vs. Eur & -9.287 & 0.000 & ** \\
\hline \multirow[t]{3}{*}{ bio03 } & Cat vs. Mal & -49.853 & 0.000 & ** & bio13 & Cat vs. Mal & -7.091 & 0.000 & ** \\
\hline & Eur vs. Mal & -3.331 & 0.001 & ** & & Eur vs. Mal & 7.382 & 0.000 & ** \\
\hline & Cat vs. Eur & 10.384 & 0.000 & ** & & Cat vs. Eur & 2.042 & 0.045 & * \\
\hline \multirow[t]{3}{*}{ bio04 } & Cat vs. Mal & 6.892 & 0.000 & $* *$ & bio14 & Cat vs. Mal & 28.891 & 0.000 & ** \\
\hline & Eur vs. Mal & -6.822 & 0.000 & ** & & Eur vs. Mal & 19.528 & 0.000 & ** \\
\hline & Cat vs. Eur & 7.866 & 0.000 & ** & & Cat vs. Eur & -7.488 & 0.000 & ** \\
\hline \multirow[t]{3}{*}{ bio05 } & Cat vs. Mal & -14.308 & 0.000 & ** & bio15 & Cat vs. Mal & -56.176 & 0.000 & ** \\
\hline & Eur vs. Mal & -18.726 & 0.000 & ** & & Eur vs. Mal & -20.854 & 0.000 & ** \\
\hline & Cat vs. Eur & 1.985 & 0.051 & * & & Cat vs. Eur & -11.960 & 0.000 & ** \\
\hline \multirow[t]{3}{*}{ bio06 } & Cat vs. Mal & 0.219 & 0.827 & & bio16 & Cat vs. Mal & -25.362 & 0.000 & ** \\
\hline & Eur vs. Mal & -1.614 & 0.111 & & & Eur vs. Mal & 4.843 & 0.000 & ** \\
\hline & Cat vs. Eur & 3.494 & 0.001 & ** & & Cat vs. Eur & 3.384 & 0.001 & ** \\
\hline \multirow[t]{3}{*}{ bio07 } & Cat vs. Mal & -10.441 & 0.000 & ** & bio17 & Cat vs. Mal & 38.226 & 0.000 & ** \\
\hline & Eur vs. Mal & -7.985 & 0.000 & ** & & Eur vs. Mal & 22.097 & 0.000 & ** \\
\hline & Cat vs. Eur & 19.336 & 0.000 & ** & & Cat vs. Eur & 4.226 & 0.000 & ** \\
\hline \multirow[t]{3}{*}{ bio08 } & Cat vs. Mal & 22.819 & 0.000 & $* *$ & bio18 & Cat vs. Mal & 34.266 & 0.000 & ** \\
\hline & Eur vs. Mal & -2.522 & 0.014 & * & & Eur vs. Mal & 17.861 & 0.000 & ** \\
\hline & Cat vs. Eur & -1.891 & 0.062 & & & Cat vs. Eur & -13.142 & 0.000 & ** \\
\hline \multirow[t]{2}{*}{ bio09 } & Cat vs. Mal & -4.360 & 0.000 & ** & bio19 & Cat vs. Mal & -42.780 & 0.000 & ** \\
\hline & Eur vs. Mal & -16.075 & 0.000 & ** & & Eur vs. Mal & 2.824 & 0.006 & * \\
\hline
\end{tabular}

* Significant value; ** Significant value using Bonferroni correction.

(Ávila), El Jerte valley (Cáceres) and Sierra de S. Vicente (Toledo), but the phytosanitary authorities have effectively eliminated this pest from this area by cutting and burning all the early galls. Therefore, this area is not included in the distribution or dispersal models. In Table 1, there are the ranges in altitude and climatic variables recorded for the areas where D. kuriphilus is currently present, which are used as an approximation of the ecological characteristics of this exotic cynipid in Spain. The Madrid hotspot (10) was not included in the comparison of regions since only two records of the presence of D. kuriphilus are recorded for this hotspot. The comparison of the bioclimatic values for the different regions revealed significant differences between most of the values and wide variation in all bioclimatic variables among the regions, indicating that this species occurs in areas with very different climatic conditions (Table 3).

\section{Models of dispersal of $D$. kuriphilus}

The dispersion model predicts that the area of infested chestnut trees in Spain is expected to increase over the next thirty-seven-years (2019-2055) (Fig. 1B). The maps also show the rapid spread of this cynipid across Spain from first presence to saturation between the years 2032 and 2041, when the potential occupation curves for both annual dispersal rates become asymptotic (Fig. 1C). This deceleration of potential occupation would hypothetically leave only $4 \%$ of Spanish forests not infested with $D$. kuriphilus, indicating the theoretical advance and final distribution of this species in Spain. This pattern only occurs because of the disjunct distribution of $C$. sativa on the Iberian Peninsula, with only chestnut forests in the centre of the Iberian Peninsula remaining uninfested via SDD. However, these forests would still be vulnerable to new $D$. kuriphilus LDD events. The declining curves of the mean and maximum dispersal were adjusted to a reciprocal form with correlation coefficients of 0.99 for each annual dispersal rate. However, they have a breakpoint at $\mathrm{x}_{6.6 \mathrm{~km}}=2041$ and $\mathrm{x}_{11 \mathrm{~km}}=2032$ in terms of the mean and maximum dispersal, respectively, with both models predicting constant dispersal and an asymptote at $52,317.5 \mathrm{~km}^{2}$ at the end of this period. Considering these predictions, only $\approx 20.7 \%$ of the total area of chestnut forest in Spain would not be infested with $D$. kuriphilus. The equations for the best fitting curves for the theoretical decrease in area for mean and maximum dispersal up to a particular year are as follows:

$$
\begin{aligned}
& y_{6.6 \mathrm{~km}}=\frac{1}{-1.69 E^{-3}+8.378 E^{-7} x} \\
& y_{11 \mathrm{~km}}=\frac{1}{-2.863 E^{-3}+1.419 E^{-6} x}
\end{aligned}
$$

where $y$ is the area of chestnut forest without $D$. kuriphilus, and $x$ a particular year. The first equation is for mean dispersal and the second for maximum dispersal. 

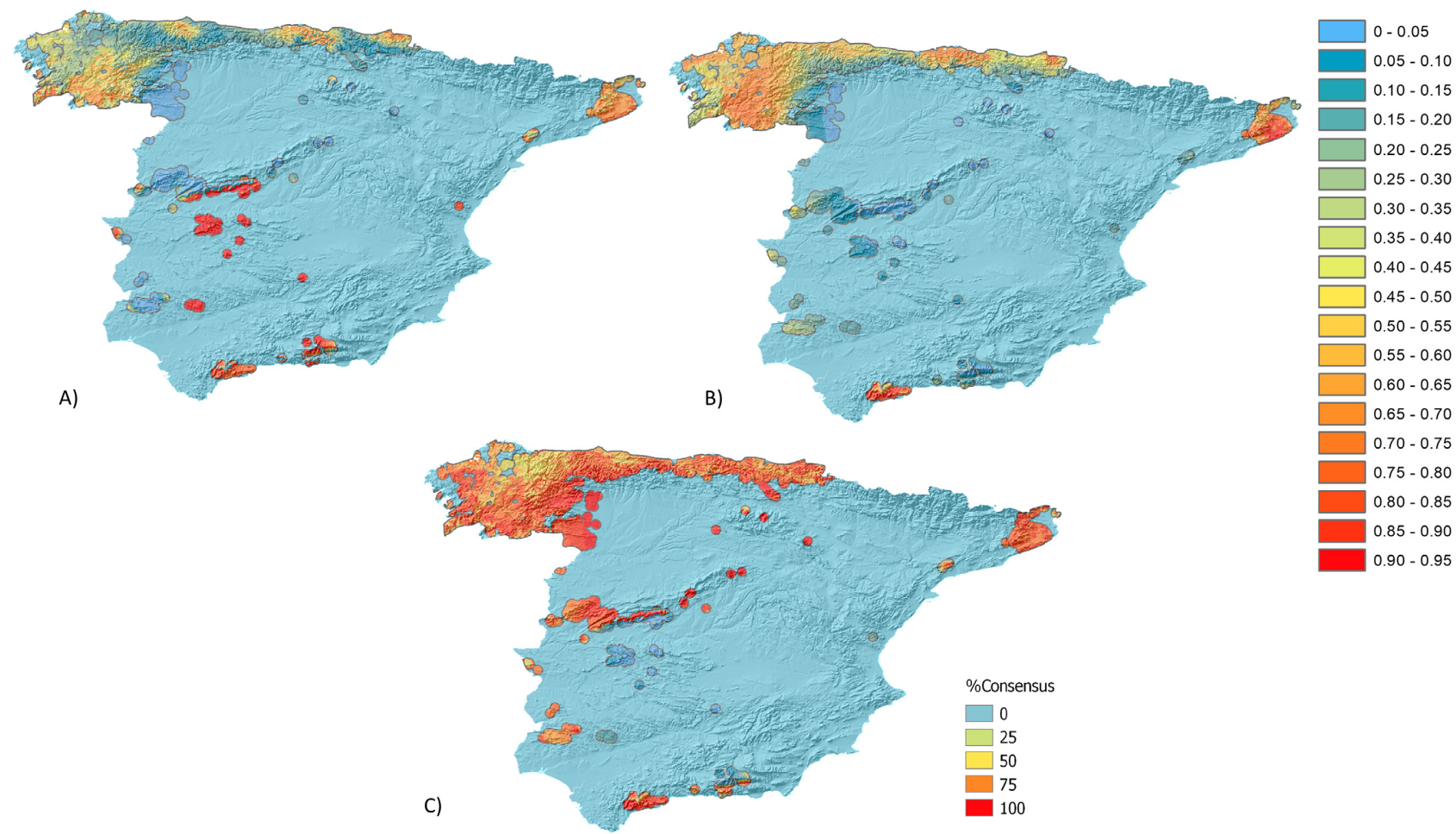

C)

Fig. 3. Maps showing the predicted potential distribution of $D$. kuriphilus in Spain: (A) generalized additive model map, (B) consensus model map, $(C)$ map of the percentage dissimilarity in the areas predicted by the two models. Areas bounded by black lines indicate the total area of $C$. sativa forest in Spain.

The distribution maps for different years (Fig. 1B) show the patterns of distribution of D. kuriphilus throughout Spain, with a considerable increase in the area infested in the northwest corner of the Euro Siberian region. According to the mean dispersal model, the hotspots in the Euro Siberian region will unite into a continuously infested area in the year 2031 .

\section{Models of the distribution of $\boldsymbol{D}$. kuriphilus}

The maps of the potential distribution of D. kuriphilus in Spain predicted by the models are shown in Fig. 3: the GAM (Fig. 3A) and mean CM of the GLM, ECM, MaxEnt model and RF model (Fig. 3B). The decision to separate the GAM from the CM was their higher pixel values of favourability compared to the predictions of the other four models for the west-central areas of Spain, as the average of the total ensemble of these models would resulted in a very different prediction for areas in west-central Spain. Of the total number of pixels in this west-central area, $69 \%$ had standard deviations of between 28 and 42, resulting in areas with values of low consensus between models (Fig. 3C). In addition, GAM was not included in CM because the prediction of this model differs from those of the other models (mean Euclidean distance $=0.72$ between the GAM and other models).

Both final maps of the distribution of D. kuriphilus are similar but their suitability values per pixel differ $\left(\mathrm{R}^{2}=0.358\right)$; the GAM suitability values are mostly higher in the west-central and southern areas of Spain, but lower in the northern part. The range of variation and suitability predicted by GAM are, respectively, greater and a lower than predicted by $\mathrm{CM}\left(\mathrm{Mean}_{\mathrm{GAM}}=0.37, \mathrm{SD}_{\mathrm{GAM}}=0.31\right.$; Mean $\left._{\mathrm{CM}}=0.40, \mathrm{SD}_{\mathrm{CM}}=0.26\right)$. Very high suitability values predicted by GAM $(>0.85)$ in practically all areas in the west-central and southern Spain where C. sativa is present, whereas the high values predicted by $\mathrm{CM}$ are in the D. kuriphilus hotspots in the Mediterranean regions of Catalonia (9) and Malaga (11). The map of the percentage dissimilarity (Fig. 3C) shows the areas that are similarly predicted by GAM and CM and those with the lowest discrepancy. The predictions of the two models for these areas are similar. The comparison of the bioclimatic variables associated with D. kuriphilus presence and favourability in the different regions (Table 3) indicate they are very similar in the Euro Siberian region and differ significantly in the west-central area of Spain.

\section{DISCUSSION}

\section{Current distribution of $\boldsymbol{D}$. kuriphilus in Spain}

Dryocosmus kuriphilus effectively colonized Spain by LDD, with at least, 11 entry points between the years 2012 and 2015, and was then most likely transported from infested areas by the trade in chestnut trees. However, new hotspots of D. kuriphilus occurrence were detected, highlighting the role of LDD in the establishment of new hotspots in a region. There are currently a total of 14 such hotspots in Spain.

The main cause of the occurrence of multiple hotspots of D. kuriphilus is related to human activity and it is likely that it is driven by the transport of Castanea trees and seedlings for commercial purposes related to chestnut forestry. Such transport should be controlled and prevented 
from areas where this cynipid is known to occur or by transporting only trees that have undergone an appropriate quarantine. Many cases of invasion could be prevented by quarantine, during which the imported trees are kept at a sealed location during the period of the annual reproductive cycle of the chestnut wasp. This would be the best way to prevent further LDD of D. kuriphilus to other areas where the chestnut trees are not infested, although it would be difficult given the cryptic nature of the early galls of $D$. kuriphilus.

It is interesting that D. kuriphilus is in Madrid (10) and Pasajes (8) (Guipuzcoa, in the north of Spain), as these areas are isolated and its arrival there must be a result of city-wide LDD events. This is also recorded for the hotspots at Lanjarón (12) and Prades (13). Specifically, in the city of Madrid, this cynipid is restricted to the Royal Botanical Garden Alfonso XIII of Ciudad Universitaria (Madrid) and the Royal Botanical Garden of Madrid. These locations are surrounded by urban areas, and the last chestnut trees that were planted in these green spaces more than 3 years ago (2012) came from El Bierzo (1\&4), where this cynipid was first recorded in 2017 . This could indicate that LDD in this case is due to a factor other than the transport of chestnut trees, such as, the transport of other propagules. In addition, sporadic and intermittent hosts can have a profound effect on the dispersal of $D$. kuriphilus (Rieske, 2007) and it is likely there are other unknown factors that affect the spread of cynipids. The presence of $D$. kuriphilus at Pasajes could have been due to the transport of chestnut trees into this area, although it is also possible that it was by a sequence of SDD events from France. However, there are no published georeferenced data that show how the dispersal of this cynipid has occurred in this area.

Regarding the climatic characteristics associated with $D$. kuriphilus records (Table 1), which are assumed to relate to this gall wasp's ecological requirements, they all seem to be correlated with the niche of Castanea trees. However, as these records are for three separate areas, different climatic conditions can affect the ecophysiology of this wasp and its host plant (Stone et al., 2002). The ecophysiology of the host plant can indirectly affect the cynipid and may also determine the level of suitability of each area and, therefore, it is a factor that should be taken into account. Differences between the two Mediterranean regions and the Euro Siberian region are related to high rates of precipitation and lower temperatures in the Euro Siberian region, while the opposite occurs in other regions. As $C$. sativa is widely distributed in Spain in areas not subject to prolonged droughts in summer and with well-drained and permeable soils, high precipitation, and low temperatures (Conedera et al., 2004; Pereira-Lorenzo et al., 2012), it is likely that chestnut trees in drier areas occur under worse ecological conditions, which affects tree growth and gall formation, and as a consequence are less suitable for $D$. kuriphilus (Gil-Tapetado et al., unpubl.). With respect to the two Mediterranean regions, it is not by chance that all sites are similar to one another except in terms of altitude because of the climatic compensation between latitude and altitude. However, this pattern can also occur in very cold areas in the north of Spain, where frosts occur and the viability of $C$. sativa and D. kuriphilus is likely to be less.

Overall, the models used in this paper indicate that areas that are highly suitable for $D$. kuriphilus exist in different regions independent of the difference in the variables recorded in each region. This high suitability could indicate that all these regions in Spain are suitable for D. kuriphilus (Fig. 3A)

\section{Models of dispersal of $\boldsymbol{D}$. kuriphilus}

The hypothetical distribution of $D$. kuriphilus presented in this paper (Fig. 1B) depends mainly on the presence of chestnut trees, and thus is very sensitive to changes caused by the introduction of new locations for C. sativa in Spain. The existence of non-georeferenced individuals of chestnut trees is highly likely, and they can worsen the hypothetical trend in dispersal identified in this paper. This possibility highlights the importance of knowing the distribution of C. sativa and indicates that it is indispensable that all these trees in Spain are georeferenced in order to achieve a highly accurate monitoring of the status of the pest cynipid. The theoretical final distribution of D. kuriphilus in Spain in the year 2055 indicates that two-thirds of the chestnut trees will be infested by this wasp. These first approximations of the possible future framework of spread of D. kuriphilus in Spain also indicate that the high dispersal ability of $D$. kuriphilus may be a major concern for chestnut forestry. However, many parameters that affect the dispersal of this wasp are still unknown, and others cannot be taken into account either because they are analytically complex or a lack of information. Therefore, the parameters that determine the presence of $D$. kuriphilus are related to their probability of establishment or infestation (Jerde \& Lewis, 2007), their intrinsic population growth rate (Neubert \& Caswell, 2000) and natural or artificial barriers and elements of resistance, such as wind direction or the presence of urban structures that may affect the rate of dispersal, as well as the frequency of introductions and size of propagules. Another factor to take into account is the sensitivity of $D$. kuriphilus to the volatiles produced by chestnut trees (Germinara et al., 2011), similar to what occurs in other galling insects, such as fig wasps (Chalcidoidea: Agaonidae) (Ahmed et al., 2009) and other cynipids, such as $A n$ tistrophus rufus Gillette, 1891 (Tooker et al., 2002). These volatiles may affect the dispersal of this species and may attract individuals to specific areas where there are high densities of chestnut trees or with particular characteristics. Indeed, attractant and repellent volatiles and wind speed and direction are factors that increase the complexity of the patterns of dispersal.

The climatic conditions of the regions included in this study are very different (see Table 3 ), presumably indicating that $D$. kuriphilus is not limited by ecological requirements apart from the presence of Castanea trees. As a consequence of LDD events due to human activity in Spain (see Fig. 1A), and since D. kuriphilus can become established in any chestnut forest, this cynipid could occur in better or worse areas depending on its ecological niche. 
The above limitations may have skewed the results of this study but may also indicate how the dispersal of $D$. kuriphilus is not ecologically restricted except by the spatial configuration of $C$. sativa trees and that the maximum distance D. kuriphilus can spread and the areas it is potentially able to colonize each year is determined by its SSD. Within this framework, the stabilization of the infested area may occur quickly, and, in the absence of control measures and based on the dispersal rate of $D$. kuriphilus, the spread should end in 2032 if there are no new infestation hotspots due LDD events. These two types of dispersal are the most important and influential determinants of the patterns of dispersion (Liebhold \& Tobin, 2008) because new introductions can modify all the predictions based on SDD (Gilioli et al., 2013).

Although all the data on the presence of D. kuriphilus was collected in 2018, the monitoring of specific areas of Spain for D. kuriphilus has continued, especially in the areas of Malaga (11), West and South Galicia and El Bierzo (1\&4). Predictions of the rates of spread noticeably differ, being greater in reality than that predicted by the models, even though the parameters included in these models are not restrictive.

\section{Models of the distribution of $D$. kuriphilus}

The models are limited in their predictions as many variables were not included due to a lack of data, such as, the biotic interactions between autochthonous fauna (Zimmermann et al., 2010), chalcid parasitoids of oak gall communities, and the experimental release of biocontrol species and the natural enemy, T. sinensis, in specific areas, or other variables that are not measurable, such as local wind direction and the fitness of individual chestnut trees. The variables considered are those associated with summer conditions, the only period in the cynipid cycle when this insect experiences the environment outside of the microenvironment of the gall (Yasumatsu, 1951; Bernardo et al., 2013). As cynipid larvae develop within galls, the climatic conditions in other seasons affect Castanea tree gall tissues but do not directly affect the wasp, which reduces the effects of some of the variables in ecological niche models of the requirements of $D$. kuriphilus.

The different models (Fig. 3A, B) predict different suitability values for different areas in Spain. The GAM (Fig. 3A) indicates that the west-central and southern areas of Spain are the most suitable areas for D. kuriphilus. However, there are also areas of high suitability near the northern hotspots of D. kuriphilus, which greatly affect the predictions of the model for these areas, perhaps due to a commission error, and decreases the predictive potential of this analysis. Based on this model, the zones in the west-central areas of Spain, where D. kuriphilus is currently not present and potentially free of SDD events are the areas likely to experience the greatest theoretical settlement given their high suitability. Thus, preventing LDD events in this area is critical because $D$. kuriphilus cannot reach this highly suitable area by SDD. Therefore, a special monitoring of the transportation of $C$. sativa trees in these areas should be developed in order to prevent $D$. kuriphilus spreading into these chestnut forests. In fact, LDD events are reported for these areas (sites of Ávila, Cáceres and Toledo provinces), where developing galls of $D$. kuriphilus galls were detected, but quickly destroyed by the forestry authorities. Its presence there was not included in the models because galls were destroyed before adult emergence, making it impossible for it to disperse and become established in the west-central area of Spain. The CM (Fig. 3B) indicates that the hotspots in Catalonia (9) and Malaga (11) are the areas with the highest suitability; however, most of the northern chestnut forests also have high values. Unlike GAM, CM indicates that all of the chestnut tree areas in the northern part of Spain are very suitable, not only those close to where the pest is recorded. This fact may indicate that most of Spain is suitable for D. kuriphilus; however, there are differences in the levels of these high values. The CM may indicate that Mediterranean regions have the best conditions and are the most suitable areas for D. kuriphilus, possibly due to their high or moderate temperatures, which favour the development of this species (Bonsignore \& Bernardo, 2018). Differences between the Euro Siberian and Mediterranean regions (Tables 1 and 3) include hotter temperatures and lower precipitation in the latter and greater probability of frost occurring during winter in the former, negatively affecting chestnut development (Casasoli et al., 2004). Therefore, the concept of suitability used here is based on the environmental conditions that could affect the life cycle of $D$. kuriphilus, especially those that can modify its development in chestnut forests. As discussed previously the ecological requirements of chestnut trees are also highly suitable for this pest and coincide with predictions of CM of intermediate rates of precipitation and mild temperatures in all the chestnut forests in Spain (Table 1). These are the optimal habitat conditions for $C$. sativa. The map of the percentage dissimilarity in the areas predicted by the two models (Fig. 3C) shows that they agree in terms of the suitability values in most of the region except the west-central areas. Although there are differences in these areas, the models similarly predict high or low suitability values in most of the zones, even if there are a few differences between them, for example, in Malaga (11) and West and South Galicia and El Bierzo (1\&4).

The two models agree in that certain areas are of high suitability (Fig. 3C), specifically the previously mentioned hotspots. In these areas it is very likely that the conditions are optimal for D. kuriphilus, since five ecological niche models indicate these areas are highly suitable. It is crucial to manage these highly suitable areas, the main D. kuriphilus hotspots, using biological control based on different methods, such as the introduction of its natural enemy, $T$. sinensis, in order to mitigate this gall wasp adverse effects on the production of chestnuts in these regions. That an area is predicted to be of low suitability does not indicate that D. kuriphilus will not become established in these areas; instead, they indicate that the vigour or fitness of C. sativa and D. kuriphilus is likely to be reduced or adversely affected by the environment in these areas and that these populations are more limited ecologically than those 
in areas that are more suitable. This low suitability might be reflected in D. kuriphilus inducing smaller or more irregular shaped galls. In addition, it is possible that the suboptimal conditions in these areas will also will prevent $T$. sinensis from becoming established or thriving there. Although the models do not predict areas of low suitability near hotspots, it is possible that a gradient in high suitability could affect the establishment of $T$. sinensis. This fact, together with the information mentioned in Quacchia et al. (2008), could explain the differences in the successful establishment of $T$. sinensis in different areas.

In conclusion, in Spain the spread and infestation of chestnut forests by $D$. kuriphilus is predicted by using models that are based on the distribution of chestnut forests in this area; in addition, this study is the first attempt to understand the spread and habitat selection behaviour of D. kuriphilus in this area. The climatic characteristics in the areas where this pest is present do not seem to be important, with the only factor limiting its dispersal and distribution, the presence of chestnut trees. The models, however, indicate areas of greater or lesser suitability where D. kuriphilus could occur under different conditions and possibly behave differently. The models of distribution show that because of the configuration of their spatial distribution in this region approximately half of the Castanea forests in Spain are likely to be colonized by D. kuriphilus as a result of SDD and predict two scenarios for the areas that are highly suitable. Areas close to where D. kuriphilus is known to be present are the most likely to be colonized by this pest, however, the occurrence of new LDD events resulting in this pest arriving from another country, the main type of dispersal of $D$. kuriphilus between countries, could greatly change the situation.

ACKNOWLEDGEMENTS. We acknowledge all persons and institutions that collaborated in the collection of presence data for D. kuriphilus, O. Gavira, M.J. Lombardero of the University of Santiago de Compostela; J. Andoni Zabala of Diputación Foral de Bizkaia; R. Vallejo Bombín, Jefe de Área de Inventario y Estadísticas Forestales; J. Heras Dolader of the Direcció General del Medi Natural i Biodiversitat: S. Gutiérrez of Dirección General de Montes y Conservación de la Naturaleza; A. Pulido of Junta de Andalucía; P. del Estal of the University Politécnica of Madrid, C. Rey, P.A. Refoyo Román, D. Padilla and A. Ordóñez, J.M. Sesma, I. Gómez and Á. Izuzquiza of Biodiversidad Virtual. They provided the data and information necessary for this study.

\section{REFERENCES}

Aebi A., Schönrogge K., Melika G., Alma A., Bosio G., Quacchia A., Picciau L., Abe Y., Moriya S., Yara K., Seljak G., Stone G.N. 2006: Parasitoid recruitment to the globally invasive chestnut gall wasp Dryocosmus kuriphilus. In Ozaki K., Yukwa J., Ohgushi T. \& Price P.W. (eds): Ecology and Evolution of Galling Arthropods and their Associates. Springer, Tokyo, pp. 103-121.

Aebi A., Schönrogge K., Melika G., Quacchia A., Alma A. \& STONE G.N. 2007: Native and introduced parasitoids attacking the invasive chestnut gall wasp Dryocosmus kuriphilus. EPPO Bull. 37: 166-171.

Ahmed S., Compton S.G., Butlin R.K. \& Gilmartin P.M. 2009: Wind-borne insects mediate directional pollen transfer between desert fig trees 160 kilometers apart. — Proc. Natl. Acad. Sci. USA 106: 20342-20347.

Avtzis D.N. \& Matosevic D. 2013: Taking Europe by storm: a first insight in the introduction and expansion of Dryocosmus kuriphilus in central Europe by mtDNA. - J. For. Soc. Croatia 137: 387-394.

Bernardo U., Iodice L., Sasso R., Tutore V.A., Cascone P. \& Guerrieri E. 2013: Biology and monitoring of Dryocosmus kuriphilus on Castanea sativa in Southern Italy. - Agric. For. Entomol. 15: 65-76.

Bonal R., Vargas-Osuna E., Mena J.D., Aparicio J.M., Santoro M. \& Martín A. 2018: Looking for variable molecular markers in the chestnut gall wasp Dryocosmus kuriphilus: first comparison across genes. - Sci. Rep. 8: 5631, 9 pp.

BonsignoRe C.P. \& Bernardo U. 2018: Effects of environmental parameters on the chestnut gall wasp and its complex of indigenous parasitoids. - Sci. Nat. 105: 20, 14 pp.

BVdb (BIODIVERSIDAd Virtual database) 2018a: Insectarium Virtual. URL: http://www.biodiversidadvirtual.org/insectarium (last accessed 22 May 2018).

BVdb (Biodiversidad Virtual database) 2018b: Herbarium Virtual. URL: http://www.biodiversidadvirtual.org/herbarium (last accessed 22 May 2018).

Breiman L. 2001: Random forests. - Mach. Learn. 45: 5-32.

Breiman L. \& Cutler A. 2018: RandomForest. Breiman and Cutler's Random Forests for Classification and Regression ( $R$ package). URL: https://cran.r-project.org/web/packages/randomForest/randomForest.pdf

Brussino G., Bosio G., Baudino M., Giordano R., Ramello F. \& MeliKa G. 2002: Dangerous exotic insect for the European chestnut. - Informat. Agrar. 58: 59-61.

CABI (Centre for Agriculture and Biosciences InternationAL) 2015: Invasive Species Compendium CABI Datasheets Dryocosmus kuriphilus. URL: http://wwwcabiorg/isc/datasheet/20005 (last accessed 22 Aug. 2018).

Casasoli M., Pot D., Plomion C., Monteverdi M.C., Barreneche T., LAUTERI M. \& VilLaNi F. 2004: Identification of QTLs affecting adaptive traits in Castanea sativa Mill. - Plant Cell Environ. 27: 1088-1101.

Conedera M., Manetti M.C., Giudici F. \& Amorini E. 2004: Distribution and economic potential of the sweet chestnut (Castanea sativa Mill) in Europe. - Ecol. Mediterr. 30: 179-193.

COOPER W.R. \& RIESKE L.K. 2007: Community associates of an exotic gallmaker, Dryocosmus kuriphilus (Hymenoptera: Cynipidae), in Eastern North America. - Ann. Entomol. Soc. Am. 100: 236-244.

EFSA (European Food Safety Authority) 2010: Risk assessment of the oriental chestnut gall wasp, Dryocosmus kuriphilus for the EU territory and identification and evaluation of risk management options. - EFSA J. 8: 16-19.

EPPO (European Plant Protection Organization) 2012: First Report of Dryocosmus kuriphilus in the Czech Republic URL: https:/gd.eppo.int/reporting/article-1968 (last accessed 06 Jun. 2016).

EPPO (European Plant Protection Organization) 2014: First report of Dryocosmus kuriphilus in Portugal URL: https:// gd.eppo.int/reporting/article-2823 (last accessed 06 Jun. 2016).

ESRI (Environmental Systems Research Institute) 2010: ArcGis 10.0 Geographical Information System URL: http://www. esri.es/es/ (last accessed 22 Aug. 2018).

FARBER O. \& KADMON R. 2003: Assessment of alternative approaches for bioclimatic modeling with special emphasis on the Mahalanobis distance. - Ecol. Model. 160: 115-130.

Fernandez-Conradi P., Borowiec N., Capdevielle X., Castagneyrol B., Maltoni A., Robin C., Selvi F., Van Halder I., 
Vétillard F. \& JACTel H. 2017: Plant neighbour identity and invasive pathogen infection affect associational resistance to an invasive gall wasp. - Biol. Invas. 20: 1459-1473.

Ferracini C., Bertolino S., Bernardo U., Bonsignore C.P., FaCcoli M., Ferrari E., Lupi D., Maini S., Mazzon L., Nugnes F., Rocco A., Santi F. \& Tavella L. 2018: Do Torymus sinensis (Hymenoptera: Torymidae) and agroforestry system affect native parasitoids associated with the Asian chestnut gall wasp? - Biol. Control 121: 36-43.

Fielding A.H. \& BeLl J.F. 1997: A review of methods for the assessment of prediction errors in conservation presence/absence models. - Environ. Conserv. 24: 38-49.

GBIF Data Portal 2018: Castanea sativa. URL http://www. GBIF.net (last accessed 22 May. 2018).

Gehring E., Bellosi B., Quacchia A. \& Conedera M. 2017: Assessing the impact of Dryocosmus kuriphilus on the chestnut tree: branch architecture matters. - J. Pest Sci. 91: 189-202.

Germinara G.S., De Cristofaro A. \& Rotundo G. 2011: Chemical cues for host location by the chestnut gall wasp, Dryocosmus kuriphilus. - J. Chem. Ecol. 37: 49-56.

Gilioli G., Pasqualib S., Tramontinic S. \& Riolo F. 2013: Modelling local and long-distance dispersal of invasive chestnut gall wasp in Europe. - Ecol. Model. 263: 281-290.

GRAZIOSI I. \& RIESKE L.K. 2012: Local spread of an exotic invader: using remote sensing and spatial analysis to document proliferation of the invasive Asian chestnut gall wasp. - iForest 5: 255-261.

Guisan A., Edwards JR. T.C. \& Hastie T. 2002: Generalized linear and generalized additive models in studies of species distributions: setting the scene. - Ecol. Model. 157: 89-100.

Hijmans R.J., Guarino L., Bussink C., Mathur P., Cruz M., BarRENTES I. \& RoJAs E. 2004: DIVA-GIS, Ver. 4.0. A Geographic Information System for the Analysis of Species Distribution Data. URL: http://www.divagis.org (last accessed 22 Aug. 2018).

Hijmans R.J., Cameron S.E., Parra J.L., Jones P.G. \& Jarvis A. 2005: Very high resolution interpolated climate surfaces for global land areas. - Int. J. Climatol. 25: 1965-1978.

Hijmans R.J., Phillips S., Leathwick J. \& Elith J. 2017: dismo. Species Distribution Modeling. ( $R$ package) URL: https:// cran.r-project.org/web/packages/dismo/dismo.pdf.

Hirzel A.H., Hausser J., Chessel D. \& Perrin N. 2002: Ecological-niche factor analysis: How to compute habitat-suitability maps without absence data? - Ecology 83: 2027-2036.

Hirzel A.H., Hausser J. \& Perrin N. 2007: Biomapper 4.0 Laboratory for Conservation Biology. URL: http://www2.unilch/ biomapper/ (last accessed 22 Aug. 2018).

Hyams D.G. 2010: CurveExpert Software. URL: http://www. curveexpert.net (last accessed 22 Aug. 2018).

JERDE C.L. \& LeWIS M.A. 2007: Waiting for invasions: A framework for the arrival of nonindigenous species. - Am. Nat. 170 $1-9$.

Jiménez-Valverde A., Peterson A.T., Soberon J., Overton J.M., Aragón P. \& Lobo J.M. 2011: Use of niche models in invasive species risk assessments. - Biol. Invas. 13: 2785-2797.

JAND (Junta DE ANDALucía) 2015: Geo-Referred Data on Dryocosmus kuriphilus Presence. URL: https://www. juntadeandalucia.es/agriculturaypesca/ifapa/servifapa/ contenidoAlf?id=091a7cca-4a5e-4d56-85f6-5570dcf7b43a\&l $=$ expresiones (last accessed 22 Aug. 2018).

Liebhold A.M. \& Tobin P.C. 2008: Population ecology of insect invasions and their management - Annu. Rev. Entomol. 53: $1-542$.
Lin D., Foster D.P. \& UnGar L.H. 2011: VIF-Regression: A fast regression algorithm for large data. - J. Am. Stat. Assoc. 493: 232-247.

MAgRAMA (Ministerio de Agricultura, Alimentación y Medio AmbIENTE OF SpaIN) 2015: Red Natura 2000. URL: http://www. magrama.gob.es/es/biodiversidad/temas/espacios-protegidos/ red-natura-2000/default.aspx (last accessed 22 Aug. 2018) [in Spanish].

Maltoni A., Mariotti B., Jacobs D.F. \& TANi A. 2012: Pruning methods to restore Castanea sativa stands attacked by Dryocosmus kuriphilus. - New Forests 43: 869-885.

Matošević D., Lacković N., Melika G., Kos K., Franić I., KrisTON E. \& Rot M. 2016: Biological control of invasive Dryocosmus kuriphilus with introduced parasitoid Torymus sinensis in Croatia, Slovenia and Hungary. - Period. Biolog. 117: 471-477.

MNBC (Direcció General del Medi Natural i Biodiversitat of CAtalonia) 2015: Cartografia dels Habitats a Catalunya. Geo-referred data on Dryocosmus kuriphilus presence. URL: https://www.iberley.es/legislacion/orden-aam-355-2012-2noviembre-establecen-zonas-delimitadas-plaga-dryocosmuskuriphilus-10235217 (last accessed 22 Aug. 2018).

Moriya S., Inoue K., Otake A., Shiga M. \& Mabuchi M. 1989: Decline of the chestnut gall wasp population, Dryocosmus kuriphilus Yasumatsu (Hymenoptera: Cynipidae) after the establishment of Torymus sinensis Kamijo (Hymenoptera: Torymidae). - Appl. Entomol. Zool. 24: 231-233.

Moriya S., Shiga S. \& Adachi I. 2003: Classical biological control of the chestnut gall wasp in Japan. In Proceedings of the 1st International Symposium on Biological Control of Arthropods, Honolulu, Hawaii, January 14-18, 2002. United States Department of Agriculture, Forest Service, Washington, pp. 407-415.

Murakami Y., Toda S. \& Gyoutoku Y. 2001: Colonization of imported Torymus (Syntomaspis) sinensis Kamijo (Hymenoptera: Torymidae) parasitic on the chestnut gall wasp (Hymenoptera: Cynipidae). Success in the eighteenth year after release in $\mathrm{Ku}-$ mamoto. - Proc. Assoc. Pl. Prot. Kyushu 47: 132-134.

Nieves-Aldrey J.L. 2001: Fauna Ibérica, Vol. 16, Hymenoptera: Cynipidae. Consejo Superior de Investigaciones Científicas (CSIC), Madrid, 636 pp. [in Spanish].

Nieves-Aldrey J.L., Gómez J.F., HernándeZ-Nieves M. \& Lobo J.M. 2006: Los Cynipidae (Hymenoptera) de la Comunidad de Madrid: lista anotada, mapas de distribución, riqueza y estatus de conservación. - Graellsia 62: 371-402 [in Spanish].

Neubert M.G. \& Caswell H. 2000: Density-dependent vital rates and their population dynamic consequences. - J. Math. Biol. 41: 103-121.

Оно N. \& UMEYA K. 1975: Occurrence of the chestnut gall wasp in the People's Republic of China. - Shokubutsu Boeki 29: 463-464 [in Japanese].

Payne J.A., Menke A.S. \& Schroeder P.M. 1975: Dryocosmus kuriphilus Yasumatsu (Hymenoptera: Cynipidae), an oriental chestnut gall wasp in North America. - Coop. Econ. Insect Rep. 25: 903-905.

Pereira-Lorenzo S., Ballester A., Corredoira E., Vieitez A.M., Agnanostakis S., Costa R., Bounous G., Botta R., Beccaro G.L., Kubisiak T.L., Conedera M., Krebs P., Yamamoto T., Sawamura Y., TaKada N., Gomes-Laranjo J. \& Ramos-CabreRA A.M. 2012: Chestnut. In Badenes M.L. \& Byrne D.H. (eds): Fruit Breeding. Springer, New York, 875 pp.

Pérez-Otero R., Crespo D. \& Mansilla J.P. 2017: Dryocosmus kuriphilus Yasumatsu, 1951 (Hymenoptera: Cynipidae) in Galicia (NW Spain): pest dispersion, associated parasitoids 
and first biological control attempts. - Arquiv. Entomol. 17: 439-448.

Phillips S.J. \& Dudik M. 2008: Modeling of species distributions with Maxent: new extensions and a comprehensive evaluation. - Ecography 31: 161-175.

Phillips S.J., Anderson R.P. \& Schapire R.E. 2006: Maximum entropy modelling of species geographic distributions. - Ecol. Model. 190: 231-259.

Pujade-Villar J., Torrell A. \& Rojo M. 2013: Primeres troballes a la península Ibèrica de Dryocosmus kuriphilus (Hym., Cynipidae), una espècie de cinípid d'origen asiàtic altament perillosa per al castanyer (Fagaceae). - Orsis Organ. Sist. 27: 295-301 [in Catalan].

Quacchia A., Moriya S., Bosio G., Scapin I. \& Alma A. 2008: Rearing, release and the prospect of establishment of Torymus sinensis, biological control agent of the chestnut gall wasp Dryocosmus kuriphilus, in Italy. - Biocontrol 53: 829-839.

Quacchia A., Ferracini C., Nicholls J.A., Piazza E., Saladin M.A., Tота F., Melika G. \& Alma A. 2012: Chalcid parasitoid community associated with the invading pest Dryocosmus kuriphilus in north-western Italy. — Insect Conserv. Diver. 6: 114-123.

R Development Core Team 2008: R: A Language and Environment for Statistical Computing $R$ Foundation for Statistical Computing. URL: http://www.R-project.org (last accessed 22 Aug. 2018).
RIESKE L.K. 2007: Success of an exotic gallmaker, Dryocosmus kuriphilus, on chestnut in the USA. - EPPO Bull. 37: 172174.

RStudio TEAm 2016: RStudio: Integrated Development for $R$ RStudio. URL: http://www.rstudio.com/ (last accessed 22 Aug. 2018).

Rodríguez A., Gómez J.F. \& Nieves-Aldrey J.L. 2015: Modeling the potential distribution and conservation status of three species of oak gall wasps (Hymenoptera: Cynipidae) in the Iberian range. - J. Insect Conserv. 19: 921-934.

Statistica-StatSoft Inc 2009: STATISTICA Portable, Ver. 8.0. URL: www.statsoft.com (last accessed 22 Aug. 2018).

Stone G.N., Schönrogge K., Atkinson R.J., Bellido D. \& PujadeVILLAR J. 2002: The population biology of oak gall wasps (Hymenoptera: Cynipidae). - Annu. Rev. Entomol. 47: 633-668.

ToOKer J.F., KöNIG W.A. \& HANKs L.M. 2002: Altered host plant volatiles are proxies for sex pheromones in the gall wasp Antistrophus rufus. - Proc. Natl. Acad. Sci. USA 99: 15486-15491.

Wood S. 2018: mgcv. Mixed GAM Computation Vehicle with Automatic Smoothness Estimation (R package). https://cran.rproject.org/web/packages/mgcv/index.html

Yasumatsu K. 1951: A new Dryocosmus injurious to chestnut trees in Japan (Hym., Cynipidae). - Mushi 22: 89-93.

Zimmermann N.E., Edwards Jr. T.C., Graham C.H., Pearman P.B. \& Svenning J. 2010: New trends in species distribution modelling. - Ecography 33: 985-989.

Received April 5, 2018; revised and accepted September 10, 2018 Published online October 16, 2018 